\title{
ADVANCED TWO-PHASE PASSIVE THERMAL CONTROL DEVICES: LOOP HEAT PIPES AND PULSATING HEAT PIPES
}

\author{
Roger R. Riehl \\ Instituto Nacional de Pesquisas Espaciais-INPE \\ Divisão de Mecânica Espacial e Controle-DMC \\ Av. dos Astronautas 1758, 12227-010 \\ São José dos Campos, SP, Brasil \\ rriehl@dem.inpe.br
}

\begin{abstract}
This paper presents the development of two-phase passive thermal control devices that can be used at both ground and space applications. These devices operate by acquiring heat through their evaporation section and rejecting through their condensation section, keeping a tight control on the heat source temperature without the presence of moving parts. Recent researches with loop heat pipes (LHPs) have showed the great capability of such a device in managing high levels of heat while keeping the source temperature within certain levels. For this case, experimental tests of a LHP are presented, where the behavior related to its operation with power cycles can be evaluated and its performance can be verified. This paper also presents an investigation of a two-phase thermal control device called pulsating heat pipe (PHP) configured as an open loop. Experimental tests with different working fluids are presented, which shows the great capability of the PHP in operating at both horizontal and vertical orientations and promoting the thermal control, which is highly affected by the working fluid and geometric parameters. The experimental results presented for both devices are intended to contribute for the continuous development of these two passive thermal control devices.
\end{abstract}

Keywords: thermal control, two-phase flow, loop heat pipe, pulsating heat pipe.

\section{INTRODUCTION}

The search for reliable thermal control devices has generated interesting solutions in the past and their applications have gained a wide variety of use. Two-phase passive thermal control devices, which are related to heat pipes (HPs), capillary pumped loops (CPLs) and loop heat pipes (LHPs) have been extensively investigated due to their potential application in space environments and reduced power consumption. These devices operate passively by acquiring heat from a source and dissipating it in a sink, being able to manage large amounts of heat while keeping a tight control of the heat source temperature. This is specially important when electronic components must be kept below certain levels of temperature in space and the power available for this procedure is practically unavailable. Thus, systems that operate without moving parts are a must and that is why they have gained special attention and development in recent years.

For some applications, HPs present limitations regarding the maximum heat flux to be dissipated, which result in applying CPLs and LHPs. In this case, the region where the capillary forces are generated, which drive the working fluid, is concentrated in a capillary evaporator connected to a loop composed of smooth tubing that transport the heat to a heat rejection area, being a condenser or a space radiator. CPLs and LHPs present very similar operation and their components are: capillary evaporator, condenser, liquid and vapor lines and twophase reservoir (Fig. 1a). A volatile working fluid is responsible for transporting the heat from the source to the sink. Heat is acquired by the system evaporating the working fluid through the capillary evaporator, which is in thermal contact with the heat source and it is responsible for generating the capillary forces that will drive the fluid. The capillary forces are generated in the porous wick structure presented in the evaporator, which presents a fine pore radius. Then, vapor flows in the vapor line towards the condenser where it is condensed and flows back to the evaporator by the liquid line. In the case of LHPs, the twophase reservoir is called compensation chamber and usually does not require an active control of its temperature as necessary for CPL. The reservoir is responsible for establishing the loop operation pressure and temperature as well as the working fluid inventory in the system.

Loop heat pipes were first introduced in the former Soviet Union in the mid-80's (Maidanik et al, 1985) and showed to be a reliable passive thermal control device when compared to CPLs, mainly because its capillary evaporator is vapor tolerant and its design is more robust. LHPs present several other advantages when compared to CPLs, as the two-phase reservoir temperature does not need to be controlled and pre-conditioning procedures so common in CPLs are usually not necessary. The operating characteristics of LHPs have been reported showing the great potential in using them as thermal control devices $(\mathrm{Ku}, 1999)$. Tests under microgravity have proved the great efficiency of LHPs regarding the thermal control (Kurwitz and Best, 1997; Baker et al., 1998), showing good correlation between the ground and microgravity data. Several applications of LHPs in space missions have been successful, such as the NASA's GLAS laser instrument (Swanson and Birur, 2002) and the Mars Rovers (Birur et al., 2002). Great advances on LHP technology regarding different configurations have also been reported by Delil et al. (2003).

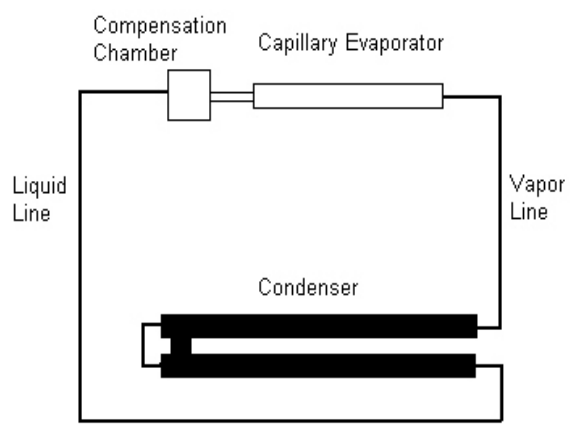


Following the same direction towards the development of alternative two-phase passive thermal control devices, an interesting option has emerged in the last decade called pulsating heat pipe (PHP), which was first introduce by Akachi et al. (1996). PHPs are two-phase thermal control devices that consist of a simple meandering capillary tube bent with several curves forming several parallel channels, without the presence of an internal wick structure, so common in regular HPs, CPLs and LHPs. The channels are formed from capillary tubings with partially filled working fluid, responsible for acquiring the heat from a source and dissipating it in a sink. PHPs can be potentially applied in several thermal control problems, such as microelectronics, but they have gained special interest for use in microgravity conditions, in order to homogenize the temperature along space radiators as well as for the passive thermal control of components. PHPs are mainly influenced by sensible heat transfer and the fluid evaporation generates vapor slugs and liquid plugs that will drive the fluid, causing both flow and temperature oscillations (Zhang and Faghri, 2002).

There are at least two possible ways in which a PHP can be configured, one being as an open loop and the other as a closed loop (Figs. 1b and 1c). In the case of open loop, the PHP has one of the tubing ends pinched-off and welded, while the other end may present a valve for evacuation and charging (the valve can be pinched off later after correct charging). For the closed loop, the two ends of the PHP tube ends are connected, forming an endless loop. One advantage of the closed loop compared to the open loop PHP is that the former allows fluid circulation, while the latter allows only slug/plug oscillations. For heat dissipation, a PHP has an evaporation section (responsible for acquiring the heat from the source), a condensation section (for dissipating the heat to a sink) and it might have an adiabatic section also. Usually, the diameters involved in a PHP are quite small (capillary dimensions), which can be determined from the two-phase flow theory. This is due to the fact that the PHP operates by means of plugs-slugs formation and therefore surface tension and the gravity field can both be significant factors. By evaporating the working fluid in the evaporation section, vapor bubbles are formed and must flow towards the condensation section through the adiabatic section. In this path, the bubble may collapse or coalesce depending on the local thermohydrodynamics involved. This plug-slug dynamics generates pressure pulses that drive the working fluid, thus allowing the heat transport (Khandekar et al., 2003b).

(a) Loop heat pipe

(b) Open loop pulsating heat pipe

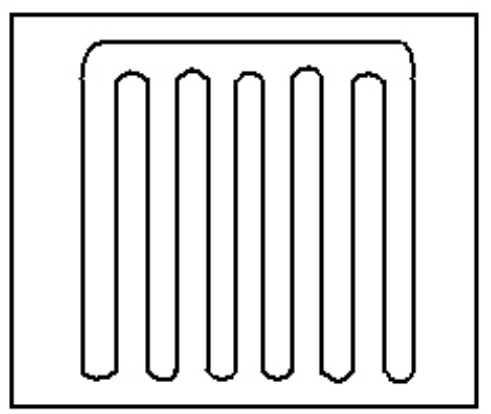

(c) Closed loop pulsating heat pipe

Figure 1. Two-phase passive thermal control devices.
Important contributions were achieved regarding the explicit understanding of the factors that influence the PHP operation and thermo-hydrodynamic characteristics when configured in a closed-loop, as well as semiempirical modeling for these devices (Charoensawan et al, 2003, Khandekar et al., 2003a and 2003b, Khandekar and Groll, 2004).

Due to its peculiar mode of operation, the PHP presents a chaotic dynamics that it is difficult to model. Quasi-equilibrium analysis of the PHP operation would be a conservative approach, as this device presents the working fluid in metastable conditions for both liquid and vapor phases (Khandekar et al., 2002; Khandekar et al., $2003 \mathrm{~b}$ ) and thus 'non-equilibrium' conditions drive the device. Quasi-stationary modeling have showed great potential in predicting PHPs operation, which was in accordance to experimental results (Borisov et al., 2002). The plug/slug flow dynamics is directly dependent on the applied power to the evaporation section, tilt angle and amount of non-condensable gases ( $\mathrm{Qu}$ and $\mathrm{Ma}, 2002)$. A mathematical model has addressed the operation of PHPs, where the characteristic chaotic behavior can be reflected which were in accordance to experimental results (Dobson, 2004). However, a more refined and realistic approach to model PHPs is required, which should not only deal with the thermal characteristics but also the hydrodynamics and flow pattern transitions observed during the operation. As many variables are still to be understood, extensive experimental investigation of these devices are required to properly model their operation characteristics.

In face of the above mentioned interesting twophase passive thermal control devices, this paper presents an experimental investigation of a LHP and a PHP configured as an open loop. The objectives of this investigation are presenting the developments achieved with a LHP designed for future space missions as a thermal control device for electronic components, satellites structures and batteries. Fundamental investigation of an open loop PHP is also presented in order to show a comparison between different working fluids on the operation of a PHP and the physics involved in this device regarding its unique operating characteristics and thermal control capabilities.

\section{LOOP HEAT PIPE EXPERIMENT}

The LHP experiment presented in this paper is part of a long term chronogram to develop this device for future space missions (Vlassov, 2003; Dutra and Riehl, 2004). Particularities of this device involve the development of a low cost LHP with an alternative working fluid, resulting in less hazard during manipulation and charging, as well as lower distillation and purification costs. The LHP must be able to operate within a temperature range of 20 and $85^{\circ} \mathrm{C}$ and the heat source temperature must not exceed $85^{\circ} \mathrm{C}$. For this range of temperature, some working fluids could be applied such as ammonia, acetone, methanol and propylene.

Following the limitations for this project, acetone has been selected as the working fluid which presents several advantages when compared to the most used working fluids, such as anhydrous ammonia. Acetone presents pressures below or close to atmospheric pressure for the operation temperature range, it shows good compatibility with the LHP materials, it is less hazard and it freezes at $93.15{ }^{\circ} \mathrm{C}$ while ammonia freezes at $78^{\circ} \mathrm{C}$ 
(Faghri, 1995).

Following the project requirements, the entire experimental setup was built in 316LASTM stainless steel tubing with the geometric characteristics described in Table 1 . The grooves were axially machine on a UHMW (Ultra-High Molecular Weight) polyethylene wick (primary) outer diameter. The evaporator housing was machined with micro threads on its inner diameter to improve the heat transfer process. Heat was applied to the capillary evaporator through an aluminum saddle $(65 \mathrm{~mm}$ x $30 \mathrm{~mm}$ x $10 \mathrm{~mm}$ thick, with a contact angle of $120^{\circ}$ ) where a kapton skin heater was attached. The heat rejection area was an aluminum heat exchanger with embedded channels, circulating a coolant (water and ethylene-glycol) at $5{ }^{\circ} \mathrm{C}$. The LHP condenser was in thermal contact to this heat exchanger through an aluminum plate $(300 \mathrm{~mm} \times 300$ $\mathrm{mm} \times 4 \mathrm{~mm}$ thick). High grade acetone with minimum purity of $99,98 \%$ was used as working fluid and all tests were performed without pre-conditioning procedures, for a controlled room temperature ranging from 18 to $20^{\circ} \mathrm{C}$. The liquid inventory for testing the LHP was 25 grams, keeping the compensation chamber with a void fraction of $50 \%$ in the cold mode.

Table 1. Geometric characteristics of the LHP.

\begin{tabular}{|c|c|c|c|c|c|}
\hline \multicolumn{2}{|l|}{ Capillary Evapurater } & \multicolumn{2}{|l|}{ Liquid Line } & \multicolumn{2}{|l|}{ Vapor Iine } \\
\hline Total Length (mm) & 100 & Outer D imeter (mm) & 4.85 & Outer Diameter ( $(\mathbf{m})$ & 4.85 \\
\hline Active Length (mm) & 65 & Inner D immeter $(\mathrm{rm})$ & 2.85 & Fmer D immetter $(\mathrm{mm})$ & 2.85 \\
\hline Oturt/Iruer Dimwter (wom) & $190 / 16.3$ & Lerghth (wm) & 850 & Lewght $(\mathrm{wm})$ & 550 \\
\hline Material & $304 \mathrm{~L}$ SS & & & & \\
\hline \multicolumn{2}{|c|}{ UFWnW Polyethylene Widk } & \multicolumn{2}{|l|}{ Condenser } & \multicolumn{2}{|l|}{ Compensation Chamber } \\
\hline Pore Radins $(1+2)$ & 6 & Orter D imeter (mm) & 4.85 & Outer Diameter (nm) & 45.0 \\
\hline Penmability $\left(\mathrm{m}^{2}\right)$ & $10^{-13}$ & Inner D iameter ( $\mathrm{mm}$ ) & 2.85 & Length & 25.0 \\
\hline Porosity $(\%)$ & 50 & Length (mm) & 1000 & Screenmesh & 200 \\
\hline Diamster (OD $/ D) \mathrm{mm}$ & $163 / 7.0$ & & & Vohme $\left(\mathrm{cm}^{3}\right)$ & 20 \\
\hline Nrmber of Axial Grooves & 15 & & & & \\
\hline
\end{tabular}

The configuration of the presented LHP was designed to promote $100 \mathrm{~W}$ of thermal control, even though it would operate at a maximum of $80 \mathrm{~W}$ as this is the maximum power required for this application. The connections of the LHP capillary evaporator and compensation chamber were welded, as the rest of the loop, using an orbital system in order to be in agreement with the requirements for space qualification procedures. A representation of the LHP tested and a cross section of the capillary evaporator are presented by Fig. 2, where the device was tested at horizontal position.

The LHP was tested on a heat load profile basis which objective was evaluating the device capability on handling changes on the heat load applied to the capillary evaporator. The range of applied power was from 1 to 80 $\mathrm{W}$, as presented by Table 2 . The level of $1 \mathrm{~W}$ is required for the LHP operating at the sleeping mode, when the thermal control is not required and startup procedures should be avoided. The LHP was fully instrumented with 20 type-T Omega thermocouples (deviation of $0.3{ }^{\circ} \mathrm{C}$ at $100^{\circ} \mathrm{C}$ ), connected to a Agilent 34920 A data acquisition system. The temperatures were acquired at a rate of 1 reading at each 3 seconds. The skin heater $(70 \times 15 \mathrm{~mm}, 14 \mathrm{Ohms})$ was connected to a DC power supply with accuracy of 1.0 $\%$. During all tests, the LHP capability on handling the heat load changes and its performance until reaching the steadystate condition were analyzed. Such analyses were important to be made due to the LHP requirement to promote the thermal management properly without presenting temperature overshooting or dryout.
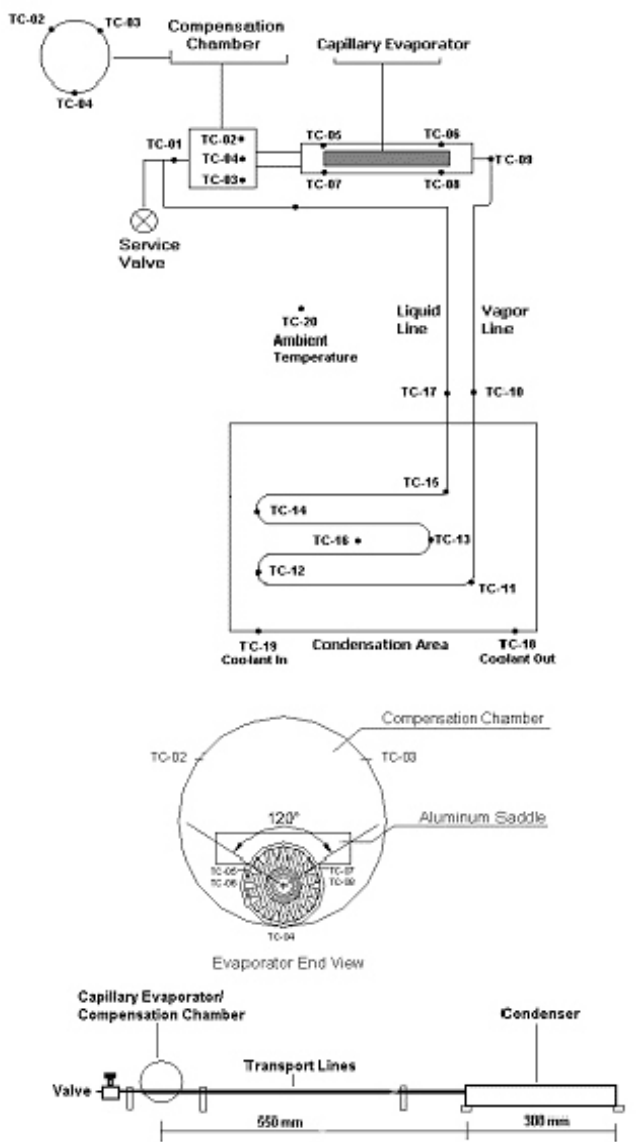

Figure 2. LHP experiment.

Table 2. Heat loads used to test the LHP.

\begin{tabular}{|ccc|}
\hline Profile & Power Levels (W) & Startup Power (W) \\
\hline 1 & $20-2-30-2-40$ & 20 \\
2 & $40-10-60-5-20-80$ & 40 \\
3 & $2-10-2-30-50-2$ & 2 \\
4 & $60-5-80-2-40-10$ & 60 \\
5 & $2-5-1-2-1-5$ & 2 \\
\hline
\end{tabular}

\section{LHP experimental results and discussion}

The LHP, named here as TCD-LHP (Thermal Control Device) presented a reliable operating during all tests, as presented by Fig. 3 . The startup procedures at both low and high heat loads were all successful at all times and during its operation the LHP did not show any tendency of temperature overshooting or capillary evaporator depriming. The heat source temperature was always kept below the maximum allowable level of $85{ }^{\circ} \mathrm{C}$ (a design parameter) and even using an alternative working fluid, the system presented continuous operation along time. The LHP presented instant startups as soon as power was applied to the capillary evaporator and fast transients when the power applied was suddenly changed. Special attention should be given to tests at low heat loads, such as Profile 5, when the LHP must operate at a very reduced power and capillary evaporator depriming is potentially enhanced, as the minimum required subcooling for its proper operation might not be achieved as the flow rate is very little. For low power levels, the heat leak on the liquid line is enough to compromise the required minimum subcooling for the proper LHP operation. However, during all tests at low power, especially at $1 \mathrm{~W}$, the LHP presented continuous operation which can be observed from the experimental test presented by Fig. 3b, as all temperatures registered variations as power was changed indicating mass flow and thus heat transport from the heat source to the sink. This 
result shows that this particular LHP presents a very reduced lower limit for its operation, which is mainly due to the reduced geometric characteristics of the capillary evaporator (active length, etc).

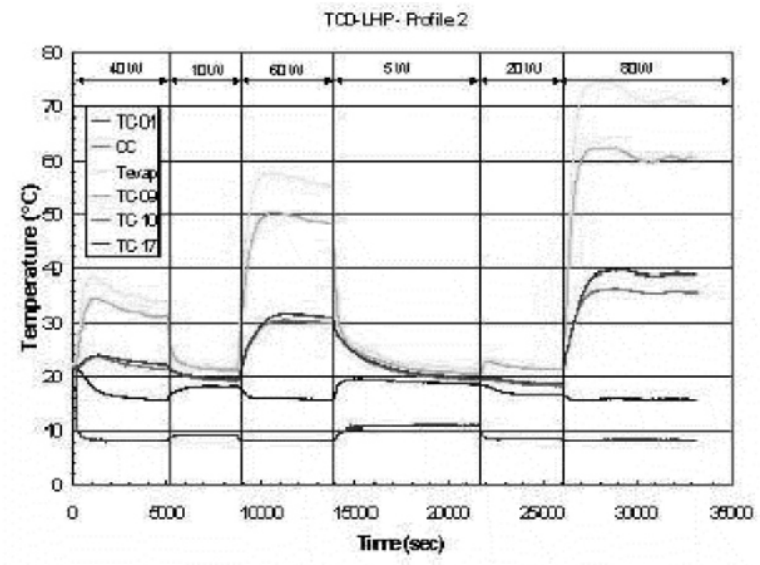

(a) Test with Profile 2

TOD-LHP-Adile 5

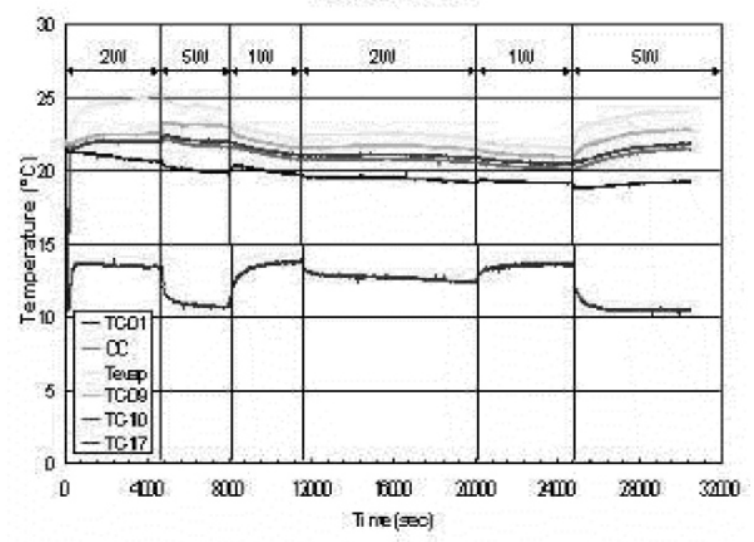

(b) Test with Profile 5

Figure 3. Experimental tests with the LHP at horizontal orientation.

The overall test results are presented in Fig. 4, where the maximum capillary evaporator temperatures and the thermal resistances are shown. The slope on the temperature presented by Fig. 4a where lower capillary evaporator temperatures are shown were due to the minimum thermal resistances observed during the tests for this particular design of the LHP, as presented by Fig. $4 \mathrm{~b}$. This slope is also related to the heat leak on the liquid line, which plays an important role on the overall LHP thermal management and must be carefully considered when designing this system. The TCD-LHP accomplished all the thermal requirements for the tests and its application in future space missions showed the great potentiality of this device in promoting the thermal control. Minimization of the thermal resistances is a must in this kind of device, which is an issue when miniaturizing the LHP sizes and reduced active lengths and wick thickness can result in severe complications for the its proper operation (Delil et al., 2003). (a) Maximum evaporator temperatures

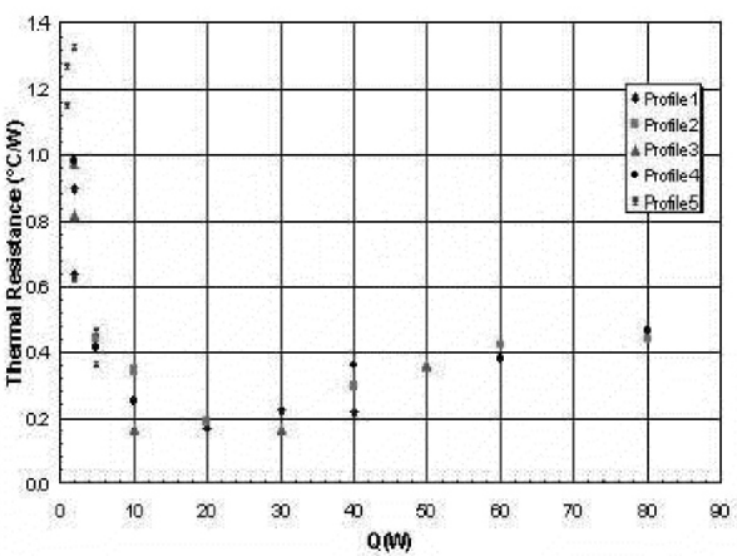

(b) Thermal resistances

Figure 4. Overall tests results for the LHP at horizontal operation.

\section{OPEN LOOP PULSATING HEAT PIPE (OLPHP) EXPERIMENT}

The OLPHP was built with copper capillary tubing with $3.0 \mathrm{~mm}$ OD and $1.5 \mathrm{~mm}$ ID and length of $4.0 \mathrm{~m}$. It was bent with 12 curves to form 13 parallel channels. One end was pinched-off and welded while the other end was connected to a service valve used for evacuation and charging, as presented by Fig. 5 .

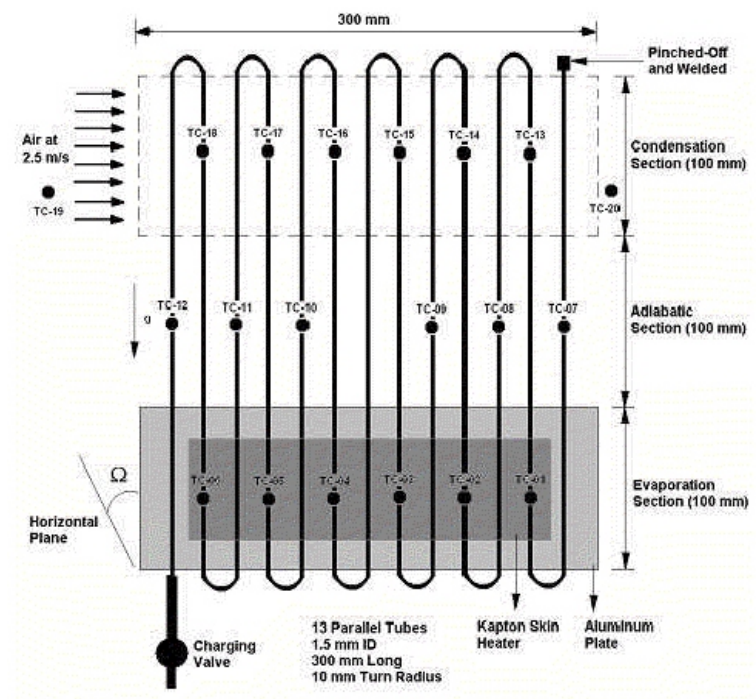

Figure 5. OLPHP test apparatus. 
The apparatus was divided in three regions: evaporation, adiabatic and condensation, each one $100 \mathrm{~mm}$ long and $300 \mathrm{~mm}$ wide. The evaporation section was in thermal contact with two aluminum plates, where a kapton skin heater ( $280 \mathrm{~mm} \mathrm{X} 25 \mathrm{~mm}, 11.5 \mathrm{Ohms}$ ) was used to deliver the heat loads. The evaporation and the adiabatic sections were thermally insulated while the condensation section was in contact to the surroundings air. The condensation was promoted by a fan able to deliver air at a velocity of $2.5 \mathrm{~m} / \mathrm{s}$. The tests were conducted in a controlled room environment, with temperatures ranging between 18 to $20^{\circ} \mathrm{C}$. The heat loads were administrated by a DC power supply with deviation of $\pm 1 \%$. Twenty type-T Omega thermocouples (deviation of $\pm 0.3{ }^{\circ} \mathrm{C}$ at $100{ }^{\circ} \mathrm{C}$ ) were used to monitor the device performance during the tests. A total of 6 thermocouples were located at each section (evaporation, adiabatic and condensation) and the remaining two were at the fan inlet and outlet. The thermocouples were connected to an Agilent 34970A data acquisition system used to monitor all temperatures, where the temperatures were read and saved in a spreadsheet. The temperatures were acquired at a rate of 1 reading at each 3 seconds.

Tests were performed for the OLPHP operating at both vertical and horizontal orientations, for three different working fluids: ethanol, methanol and acetone. The working fluids were selected according to their ClausiusClayperon relation

$$
(d P / d T)_{T_{s a t}}=i_{l v} /\left(T_{s a t} v_{l v}\right)
$$

where $i_{l v}$ is the latent heat of vaporization $(\mathrm{J} / \mathrm{kg}), T_{\text {sat }}$ is the saturation temperature $\left({ }^{\circ} \mathrm{C}\right), v_{l v}$ is the specific volume $\left(\mathrm{m}^{3} / \mathrm{kg}\right)$ and high values for the magnitude of the derivative must be achieved as PHPs are highly influenced by this parameter. The working fluid selection directly influences the maximum inner tube diameter $\left(d_{\max }\right)$, which can be estimated from the Bond number analysis

$$
B o=d_{\max } \sqrt{g\left(\rho_{l}-\rho_{v}\right) / \sigma}
$$

where $g$ is the gravity acceleration $\left(9.81 \mathrm{~m} / \mathrm{s}^{2}\right), \rho_{l}$ and $\rho_{v}$ are the liquid and vapor densities respectively $\left(\mathrm{kg} / \mathrm{m}^{3}\right)$ and $\sigma$ is the surface tension $(\mathrm{N} / \mathrm{m})$. Since PHPs operate by slug/plug motion, all conditions for generating vapor slugs must be satisfied. In this case, the Bond number must be less than or equal to 2.0 in order to promote the slug/plug oscillations in the PHP, where the $d_{\max }$ is the upper limit for the maximum tube diameter. A comparison between all the working fluid used in this investigation, regarding their $d_{\max }$ is presented in Table 3 . All working fluids had a high assay (minimum of $99.95 \%$ ) and had to go through a distillation and out-gassing processes prior to charging the OLPHP. The inventory of each fluid was correspondent to $50 \%$ of the OLPHP internal volume. The maximum evaporation temperature was limited at a range between 110 and 120 ${ }^{\circ} \mathrm{C}$, which corresponded to a maximum heat load of $50 \mathrm{~W}$ for vertical orientation tests.

Table 3. Maximum diameters for the working fluids $\left(T_{\text {sat }}\right.$ $=20^{\circ} \mathrm{C}$ ).

\begin{tabular}{|cccc|}
\hline Fluid & Ethanol & Methanol & Acetone \\
\hline$d_{\max }(\mathrm{mm})$ & 3.6 & 3.4 & 3.5 \\
\hline
\end{tabular}

\section{OLPHP experimental tests and results}

For the startup of the OLPHP, the expected behavior was similar to other two-phase thermal control devices such as CPLs and LHPs, although sometimes the start up was difficult to observe. After initiating the administration of the heat load, an increase on the evaporation section temperature would be expected with consequent drop, indicating that the slug/plug pumping action had been initiated, which would result in temperature oscillations. With an increase of the heat load, the oscillations become more intensive and it can be detected by slight temperature decreasing. This behavior was detected by Khandekar et al. (2003b) during flow observation through transparent tubes in their experiment.

During all tests, it was noticed that the slug/plug pumping initiation was occurring at different power levels as well, such as presented by Fig. 6 a for tests with ethanol. Even though few pulsations were captured by the thermocouples readings since $5 \mathrm{~W}$ of applied power, the temperature oscillations were more evident only at $25 \mathrm{~W}$. At this point, great temperature oscillations could be captured. For this specific working fluid, the temperature oscillations could be up to $8{ }^{\circ} \mathrm{C}$.

When testing the OLPHP with acetone, it could be observed that the slug/plug pumping action was initiated for $10 \mathrm{~W}$, as presented by Fig. 6b. For this working fluid, the OLPHP presented a more even temperature distribution along the evaporation, adiabatic and condensation sections. Another important aspect observed during the operation of the OLPHP with acetone was the lower evaporation section temperature at high heat load levels. This important aspect observed during the experimental tests could lead to the use of acetone at higher heat loads for the same device geometric characteristics.

Tests with methanol presented higher operation temperatures for the maximum level of heat load of $50 \mathrm{~W}$, as shown by Fig. 6c. In this case, once again the more intensive temperature oscillations of the OLPHP initiated at $35 \mathrm{~W}$, where it was also observed that the temperature oscillations could be as much as $8{ }^{\circ} \mathrm{C}$, showing an indication of chaotic dynamics of the plug/slug motion in the channels. The adiabatic section temperature presented strong fluctuations, showing that the slug/plug flow dynamics play an important role on the device thermal behavior. Figure $6 \mathrm{~d}$ presents the overall evaporation section temperatures for the three working fluids used. From the results, it could be noticed that acetone has better results for the lowest observed evaporation section temperature along with ethanol, as methanol showed higher evaporation section temperatures. From this comparison, it is possible to conclude that for higher heat loads, acetone could be stated as the best working fluid to be used. It is interesting to point that the working fluid selection is an important parameter to select the tube inner diameter in order to have the slug/plug pumping action. This parameter is also important when evaluating the best thermal behavior for an specific OLPHP related to the evaporation section (heat source) temperature.

Tests with the OLPHP operating at horizontal orientation promoted interesting results as lower evaporation section temperatures were achieved for the same heat load levels. The OLPHP showed an equivalent behavior when compared to the vertical orientation tests, where pulsations were captured by the thermocouples. The pulsations could be noticed from the temperature readings taken during the OLPHP operation and they were move 


\section{Ciência/Science}

evident, for the tests under horizontal orientation, on the adiabatic and condensation sections.

For the tests with ethanol, the temperature oscillations started at $5 \mathrm{~W}$, as presented by Fig. 7a. Comparing the experimental results for ethanol between horizontal and vertical orientation, it was observed that lower temperatures were verified and the OLPHP could operate at higher power levels.

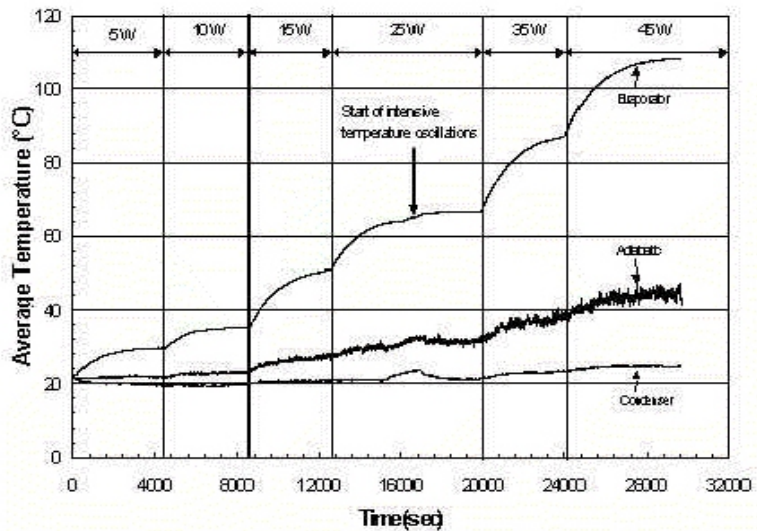

(a) Ethanol

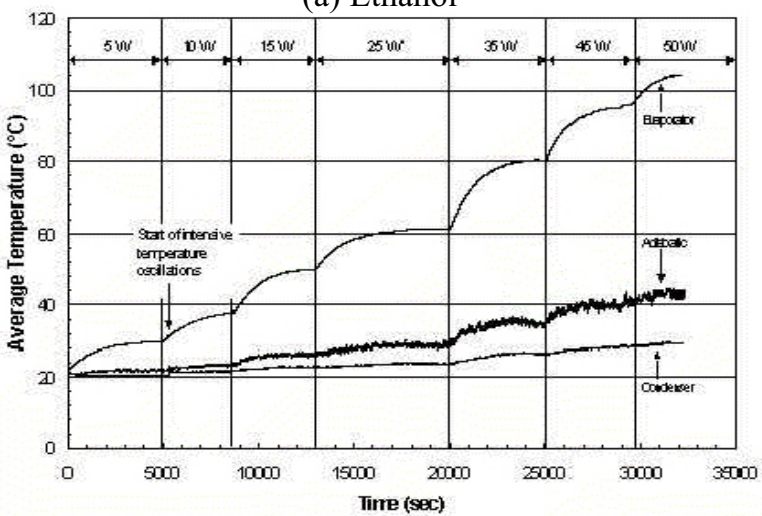

(b) Acetone

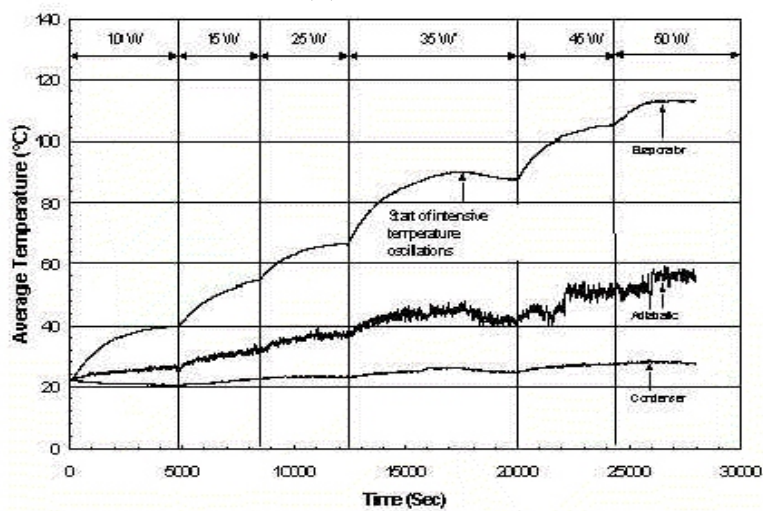

(c) Methanol

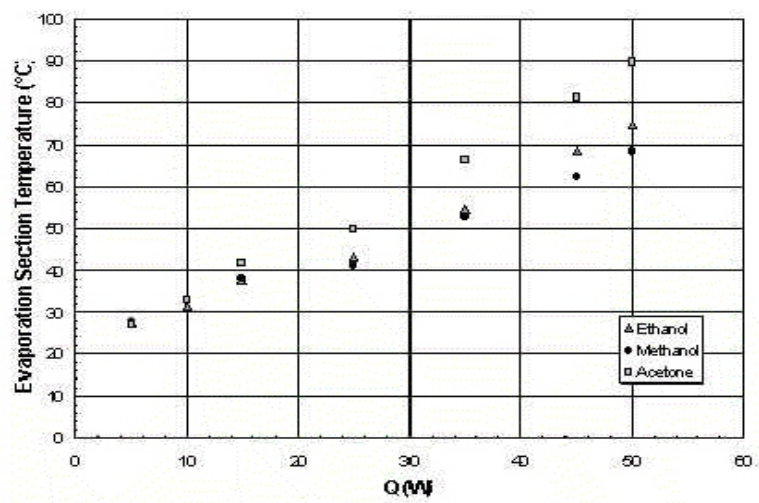

(d) Overall test results

Figure 6. OLPHP tests at vertical orientation.
Riehl et al. Advanced Two-Phase Passive ...

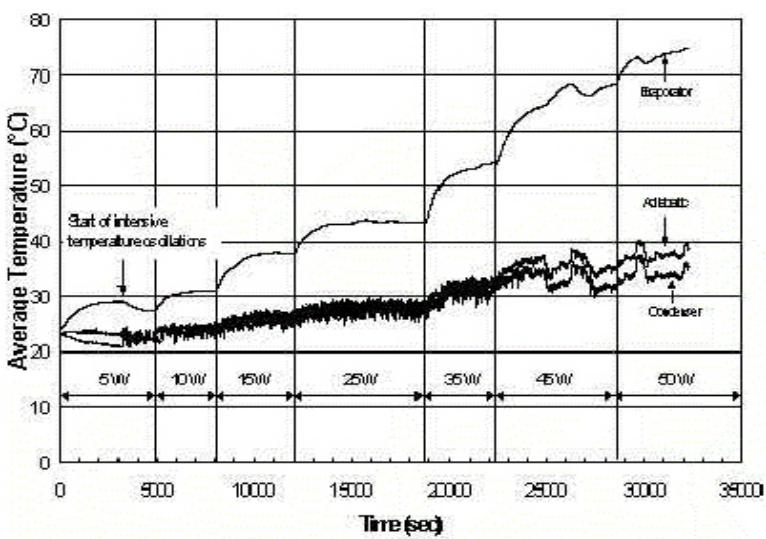

(a) Ethanol

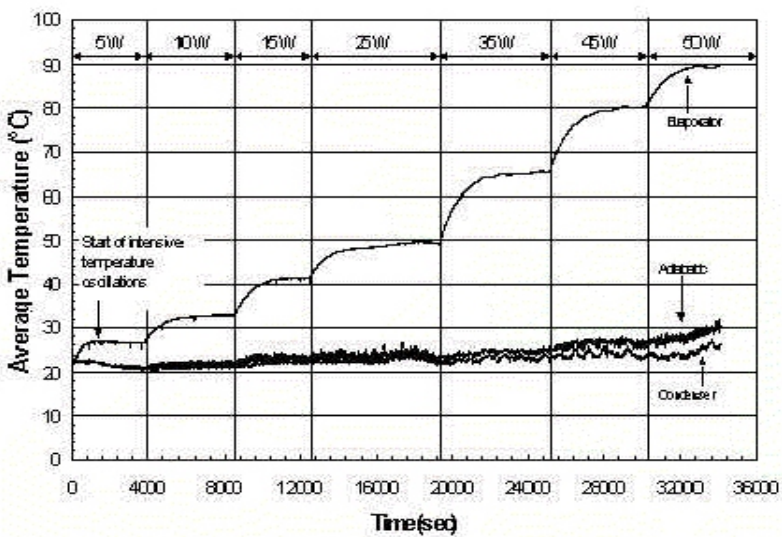

(b) Acetone

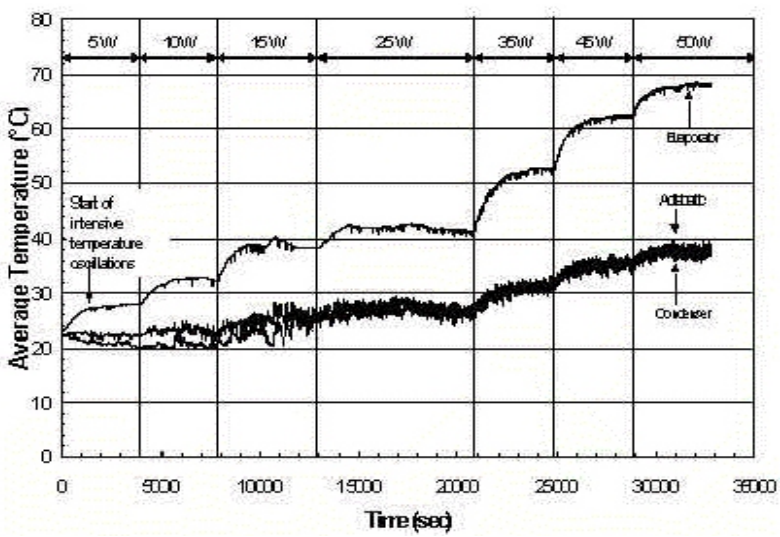

(c) Methanol

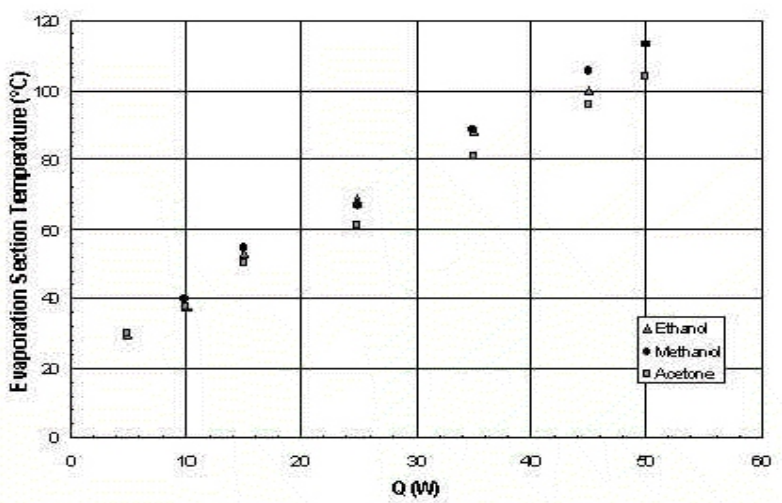

(d) Overall test results

Figure 7. OLPHP tests at horizontal orientation.

For $45 \mathrm{~W}$, great perturbations were verified which indicated instabilities during the OLPHP operation without any tendency of dryout in the evaporation section. Acetone presented better performance with more even 
temperature distribution along all sections, as presented by Fig. $7 b$, where lower temperatures were verified when compared to the tests at vertical orientation. During the tests with acetone, the intensive temperature oscillations started occurring at $5 \mathrm{~W}$.

Methanol presented intensive temperature oscillations since the beginning of the operation at $5 \mathrm{~W}$ until its termination, as presented by Fig. 7c. The OLPHP performance was considerably better when comparing the evaporation section temperatures, as at vertical orientation and $50 \mathrm{~W}$, the device presented temperature around $112^{\circ} \mathrm{C}$ while at horizontal orientation and $50 \mathrm{~W}$, the temperature was around $68^{\circ} \mathrm{C}$. For power levels above $25 \mathrm{~W}$, greater oscillations were taking place during the OLPHP operation and they started to reflect on the evaporation section temperatures where oscillations were also observed. Differently to what it was observed for the tests at vertical orientation, methanol has presented better results, followed by ethanol and acetone. Such a behavior can be observed by a comparison as presented by the overall test results on Fig. 7d. The results for tests at horizontal orientation clearly indicates that a working fluid could present a better thermal behavior operating at a certain orientation. These results are specially important to analyze as the gravity vector is not active and microgravity applications could use such a device.

The OLPHP operating at both vertical and horizontal orientations presented an average interval of oscillations as presented by Table 4, which was defined on the base of intervals between chaotic pulses. These results show that the oscillatory slug/plug motion in OLPHP is dependent on the working fluid and the applied power.

Table 4. Average interval of oscillations at $50 \mathrm{~W}$.

\begin{tabular}{|cccc|}
\hline Fluid & Ethanol & Methanol & Acetone \\
\hline Vertical $(\mathrm{sec})$ & 16 to 24 & 24 to 40 & 20 to 22 \\
\hline Vertical $(\mathrm{sec})$ & 22 to 40 & 20 to 25 & 18 to 28 \\
\hline
\end{tabular}

The experimental results, for both tests at vertical and horizontal orientations, presented the potential of using the OLPHP as a passive thermal control device. The use of different working fluids could be taken as a comparative guidance for future applications of PHPs and also for the better understanding of the phenomenon involved on their operation.

Comparing the thermal conductances for all the tests, based on the evaporation and condensation sections, Fig. 8 presents the results calculated by the following relation (with error of $\pm 5 \%$ ):

$$
C_{\text {calc }}=Q /\left(T_{\text {evap }}-T_{\text {cond }}\right)
$$

where $C_{\text {calc }}$ is the calculated thermal conductance $\left(\mathrm{W} /{ }^{\circ} \mathrm{C}\right)$, $T_{\text {evap }}$ and $T_{\text {cond }}$ are the average evaporation and condensation sections temperature $\left({ }^{\circ} \mathrm{C}\right)$, respectively. Upon evaluating the overall efficiency $(\eta)$ of the presented OLPHP the ratio of conductance is defined as:

$$
\eta=C_{\text {calc }} / C_{\text {ref }}
$$

where $C_{\text {ref }}$ is the reference thermal conductance $\left(\mathrm{W} /{ }^{\circ} \mathrm{C}\right)$ determined for the PHP operating without any working fluid as

$$
C_{r e f}=k_{C u} A / L_{e f f}
$$

where $k_{C u}$ is the copper thermal conductivity $\left(\mathrm{W} / \mathrm{m}{ }^{\circ} \mathrm{C}\right), A$ is the PHP cross-section area $\left(\mathrm{m}^{2}\right)$ and $L_{\text {eff }}$ is the effective length $(\mathrm{m})$ of the OLPHP. The range obtained for the tests under vertical orientation was between 3.3 and 5.0 and for horizontal orientation tests was between 3.6 and 11.7. These results are comparable with the best results obtained by Khandekar et al. (2002) which was 6.56 . In average, the variation of the overall efficiencies for vertical orientation was $\pm 10 \%$ and horizontal orientation was $\pm 52 \%$.

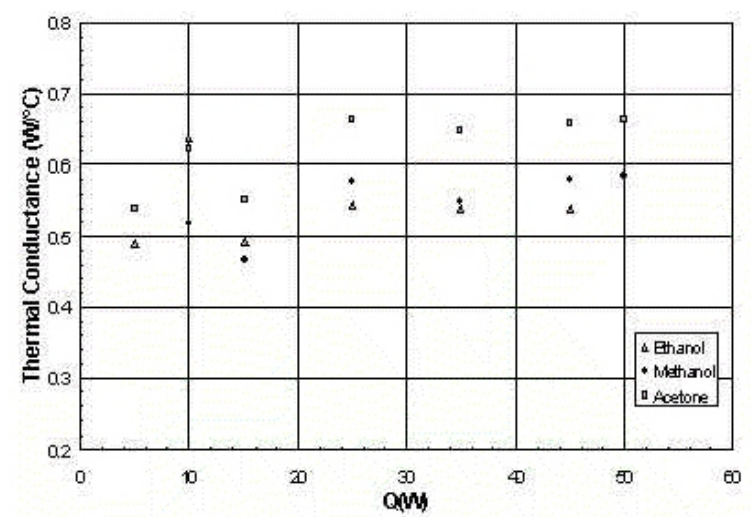

(a) Vertical

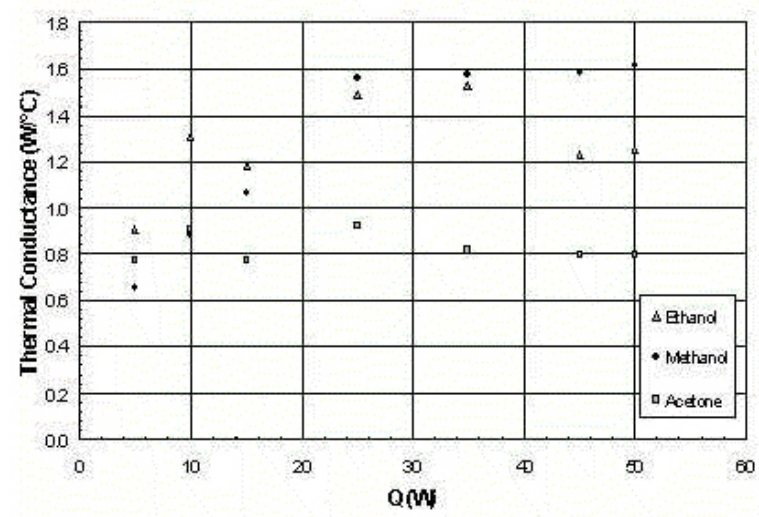

(b) Horizontal

Figure 8. Thermal conductances for the OLPHP.

\section{CONCLUDING REMARKS}

Recent advances on the development of two-phase passive thermal control devices have shown the great potentiality in using these device in space as well as in ground applications. Systems that operates by means of capillary forces generated by rejected heat from electronic components and structures indicates a wide range of possible applications with very reduced power consumption and failure possibility. However, the continuous development of this technology is required and refinements of design procedures are still necessary.

The research presented regarding the LHP experiment showed the reliable thermal behavior of this device, as temperature control of the compensation chamber was not required, as well as pre-conditioning procedures. Over the entire range of power applied to the capillary evaporator, the system presented an acceptable performance according to the requirements for the LHP regarding maximum heat source temperature, active length and working fluid. Further life tests are still necessary prior to qualifying the LHP for space applications and the development of new wick structures are undergoing, with the objective of improving the device performance. 
Following the interest in finding new two-phase passive thermal control devices, a research about a pulsating heat pipe configured as an open loop was also presented. The device showed interesting results for all three working fluids during all tests, showing remarkable operation for a device that does not present a wick structure and operates by slug/plug dynamics. The indication of a chaotic behavior of this device was observed during the tests, where great oscillations on the temperatures were verified, showing an average interval of oscillations between pulses within 16 and 40 seconds. Tests showed that the OLPHP operating at vertical orientation with acetone presented better results and at horizontal orientation, methanol presented better behavior. The OLPHP presented not too sensitive regarding the working fluid when operating at vertical orientation; at horizontal orientation tests, the device presented to be more sensible. The effective thermal conductance varied $10 \%$ at vertical orientation and $52 \%$ at horizontal orientation tests. The device presented lower evaporation section temperature for tests in horizontal orientation when compared to vertical orientation tests which could lead to use this working fluid for higher power levels.

\section{ACKNOWLEDGMENTS}

The LHP research has been supported by Fundação de Amparo a Pesquisa no Estado de São Paulo (FAPESP), grants 03/08365-6 and 03/11477-0 and the Instituto Nacional de Pesquisas Espaciais - INPE-DMC supports the development program of two-phase passive thermal control devices.

\section{REFERENCES}

Akachi, H., Polášek F., Štulc P., 1996, "Pulsating Heat Pipes", Proceedings of the $5^{\text {th }}$ International Heat Pipe Symposium, Melbourne, Australia, pp. 208-217.

Baker, C., Bienert, W., Ducao, A., 1998, "Loop Heat Pipe Flight Experiment”, SAE paper \# 981580.

Birur, G. C., Pauken, M. T., Novak, K. S., 2002, "Thermal Control of Mars Rovers and Landers Using Mini Loop Heat Pipes", Proceedings of the $12^{\text {th }}$

International Heat Pipe Conference, MoscowKostroma-Moscow, Russia, 19-24 May, pp. 189-194.

Borisov, V., Buz, V., Coba, A., Kuznetzov, I., Zacharchenko, A., Smyrnov, G. , 2002, "Modeling and Experimentation of Pulsating Heat Pipes", Proceedings of the $12^{\text {th }}$ International Heat Pipe Conference, MoscowKostroma-Moscow, 19-24 May, pp. 220-225.

Charoensawan, P., Khandekar, S., Groll, M., Terdtoon, P. , 2003, "Closed Loop Pulsating Heat Pipes Part A: Parametric Experimental Investigations", Applied Thermal Engineering, Vol. 23, pp. 2009-2020.

Delil, A. A. M., Maydanik, Y. F., Gerhart, C., 2003, "Development of a Different Novel Loop Heat Pipes within the ISTC-1360 Project", Proceedings of the $33^{\text {rd }}$ International Conference on Environmental Systems, Vancouver, Canada, July 7-10, paper \# 2003-01-2383.

Dobson, R. T., 2004, "Theoretical and Experimental Modeling of an Open Oscillatory Heat Pipe Including Gravity", International Journal of Thermal Sciences, Vol. 43, pp. 113-119.

Dutra, T., Riehl, R. R., 2004, "Loop Heat Pipe: Design and Performance During Operation", Space
Technology and Applications International Forum (STAIF), Albuquerque, NM USA, American Institute of Physics Conference Proceedings, Vol. 699, pp. 51-58.

Faghri, A., 1995, "Heat Pipe Science and Technology”, Taylor \& Francis.

Khandekar, S., Schneider, M., Schäfer, P., Kulenivic, R., Groll, M., 2002, "Thermoflyuiddynamic Study of Flat Plate Closed Loop Pulsating Heat Pipes", Microscale Thermophysical Engineering, Taylor and Francis, ISSN 1089-3954, Vol. 6/4, pp. 303-318.

Khandekar, S., Charoensawan, P., Groll, M., Terdtoon, P., 2003a, "Closed Loop Pulsating Heat Pipes Part B: Visualization and Semi-Empirical Modeling", Applied Thermal Engineering, Vol. 23, pp. 2021-2033.

Khandekar, S., Dollinger, N., Groll, M., 2003b, "Understanding pperational Regimes of Closed Loop Pulsating Heat Pipes: An Experimental Study", Applied Thermal Engineering, Vol 23, pp. 707-719.

Khandekar, S., Groll, M., 2004, “An Insight Into Thermo-Hydrodynamic Coupling in Closed Loop Pulsating Heat Pipes", International Journal of Thermal Sciences, Vol. 43/1, pp. 13-20.

Ku, J., 1999, "Operating Characteristics of Loop Heat Pipes", Proceedings of the $29^{\text {th }}$ International Conference on Environmental Systems, Denver, CO, USA, paper\# 1999-01-2007.

Kurwitz, C. and Best, F. R., 1997, "Experimental Results of Loop Heat Pipe Startup in Microgravity", American Institute of Physics Conference Proceedings, Vol. 387, No. 1, pp. 647-652.

Maidanik, Y. F., Vershinin, S., Kholodov, V., and Dolgirev, J., 1985, "Heat Transfer Apparatus", U.S. patent No. 4515209.

Qu, W., Ma, T., 2002, "Experimental Investigation on Flow and Heat Transfer of Pulsating Heat Pipes", Proceedings of the $12^{\text {th }}$ International Heat Pipe Conference, Moscow-Kostroma-Moscow, 19-24 May, pp. 226-231.

Swanson. T. D., Birur, G. C., 2002, "NASA Thermal Control Technologies for Robotic Spacecraft", Proceedings of the $12^{\text {th }}$ International Heat Pipe Conference, Moscow-Kostroma-Moscow, Russia, 19-24 May, pp. 26-34.

Vlassov, V. V., 2003, "CONTER Research and Development Program Proposal for 2003-2007 Years", National Institute for Space Research report number CONTER-D-G-EMG-002/2003, 44p.

Zhang, Y., Faghri, A., 2002, "Heat Transfer in a Pulsating Heat Pipe with an Open End", International Journal of Heat and Mass Transfer, Vol. 45, pp. 755-764. 